\title{
A Systematic Literature Review and Network Meta- Analysis Comparing Once-Weekly Semaglutide with Other GLP-1 Receptor Agonists in Patients with Type 2 Diabetes Previously Receiving Basal Insulin
}

\author{
Michal Witkowski - Lars Wilkinson - Neil Webb · Alan Weids • \\ Divina Glah · Hrvoje Vrazic (iD
}

Received: March 16, 2018 / Published online: April 30, 2018

(c) The Author(s) 2018

\begin{abstract}
Introduction: Once-weekly semaglutide is a glucagon-like peptide-1 (GLP-1) analogue that is currently available as $1.0 \mathrm{mg}$ and $0.5 \mathrm{mg}$ dose for the treatment of type 2 diabetes (T2D). Currently, no head-to-head trial investigating once-weekly semaglutide as an add-on to basal insulin vs other GLP-1 receptor agonists (GLP-1 RAs) is available. The aim of this study was to conduct a network meta-analysis (NMA) to assess the efficacy and safety of once-weekly semaglutide vs other GLP-1 RAs in patients with T2D inadequately controlled on basal insulin.

Methods: A systematic literature review was performed to identify all trials of GLP-1 RAs as an add-on to basal insulin in patients with T2D.
\end{abstract}

Enhanced Digital Features To view enhanced digital features for this article go to https://doi.org/10.6084/ m9.figshare.6106613.

Electronic supplementary material The online version of this article (https://doi.org/10.1007/s13300018-0428-y) contains supplementary material, which is available to authorized users.

M. Witkowski · N. Webb $(\bowtie) \cdot$ A. Weids DRG Abacus, Bicester, Oxfordshire, UK e-mail: nwebb@teamdrg.com

L. Wilkinson $\cdot$ H. Vrazic

Novo Nordisk A/S, Søborg, Denmark

D. Glah

Novo Nordisk Ltd., Gatwick, UK
Data at $24 \pm 4$ weeks were extracted for efficacy and safety outcomes (feasible for analysis in an NMA), including the change from baseline in glycated hemoglobin $\left(\mathrm{HbA}_{1 \mathrm{c}}\right)$, body weight, and systolic blood pressure, and the incidence of nausea, vomiting, and diarrhea. Data were synthesized using a NMA and a Bayesian framework. Results: In total, eight studies were included across the base-case analyses. The results demonstrate that once-weekly semaglutide $1.0 \mathrm{mg}$ was associated with significantly greater reductions in $\mathrm{HbA}_{1 \mathrm{c}}(-0.88 \%$ to $-1.39 \%$ vs comparators) and weight ( -1.49 to $-4.69 \mathrm{~kg}$ vs comparators) and similar odds of experiencing nausea, vomiting, or diarrhea vs all GLP-1 RA comparators. Once-weekly semaglutide $1.0 \mathrm{mg}$ was also equally effective at reducing systolic blood pressure compared with liraglutide $1.8 \mathrm{mg}$. Once-weekly semaglutide $0.5 \mathrm{mg}$ significantly reduced $\mathrm{HbA}_{1 \mathrm{c}}$ vs the majority of other GLP-1 RAs, except liraglutide $1.8 \mathrm{mg}$ QD. The odds of experiencing nausea were significantly lower with once-weekly semaglutide $0.5 \mathrm{mg}$ compared with all GLP-1 RA comparators.

Conclusion: Once-weekly semaglutide $1.0 \mathrm{mg}$ as an add-on to basal insulin is likely to be the most efficacious GLP-1 RA for reducing $\mathrm{HbA}_{1 \mathrm{c}}$ and weight from baseline after 6 months of treatment. The efficacy of once-weekly semaglutide is not associated with a significant increase in the incidence of gastrointestinal side-effects vs other GLP-1 RAs.

Funding: Novo Nordisk. 
Keywords: Basal insulin; GLP-1 receptor agonist; Glycemic control; $\mathrm{HbA}_{1 \mathrm{c}}$; Network meta-analysis; Semaglutide; Systematic review; Systolic blood pressure; Type 2 diabetes; Weight

\section{INTRODUCTION}

Type 2 diabetes (T2D) is a chronic and progressive disease associated with microvascular and macrovascular complications leading to increased morbidity and mortality $[1,2]$.

Glycemic control is the key goal in the management of $\mathrm{T} 2 \mathrm{D}$, with targets of glycated hemoglobin $\left(\mathrm{HbA}_{1 \mathrm{c}}\right)<7.0 \% \quad(53 \mathrm{mmol} / \mathrm{L})$ or $\leq 6.5 \%(48 \mathrm{mmol} / \mathrm{mol})$ defined in treatment guidelines [3-6]. Despite clear clinical guidelines for achieving glycemic control in patients with T2D $[3,7,8]$, glycemic control remains suboptimal in many patients with $\mathrm{T} 2 \mathrm{D}$ receiving insulin treatment. For example, in patients with T2D receiving basal insulin across Europe and the US, it has been estimated that $78.1 \%$ and $72.2 \%$ had inadequate glycemic control 3 and 24 months post-initiation [9]. There is significant clinical inertia in the initiation and intensification of insulin therapy among patients with poor glycemic control, and it has been estimated that only one-third achieve glycemic control 3 years after the initiation of basal insulin [10]. For patients who are inadequately controlled on basal insulin, treatment options include the intensification of insulin therapy by adding either rapid-acting bolus insulin, another oral anti-diabetic medication (OAD), or injectable glucagon-like peptide-1 receptor agonists (GLP-1 RAs) [3, 6, 7].

GLP-1 RAs are incretin mimetics that improve glycemic control with a favorable effect on body weight and a low incidence of hypoglycemia [11, 12]; GLP-1 RAs improve glycemic control when used at different stages along the T2D treatment cascade $[3,7,13]$. The differing mechanism of actions mean that GLP1 RAs can complement basal insulin therapy for the management of day-to-day blood glucose control without incurring the increased risk of hypoglycemia and weight gain associated with the addition of a bolus insulin [13]. As such, it has been suggested that the combination treatment of a GLP-1 RA and basal insulin allows achievement of the goals of anti-diabetic therapy: robust glycemic control without an increase in hypoglycemia and weight gain $[14,15]$. Combination therapy with GLP-1 RAs and basal insulin is also more effective when compared to other anti-diabetic treatment regimens [14].

Semaglutide is a new once-weekly GLP-1 analogue available at either a $1.0 \mathrm{mg}$ or $0.5 \mathrm{mg}$ dose. The clinical efficacy of once-weekly semaglutide has been extensively studied in the Semaglutide Unabated Sustainability in Treatment of Type 2 Diabetes (SUSTAIN) clinical trial program, for which data from seven global phase 3 trials have been published [16-22]. Specifically, the efficacy and safety of onceweekly semaglutide as an add-on to basal insulin ( \pm OADs) has been investigated in the SUSTAIN 5 clinical trial [20]. In this trial, onceweekly semaglutide (+ basal insulin \pm metformin) provided a superior reduction in $\mathrm{HbA}_{1 \mathrm{c}}$ levels and body weight compared with placebo (+ basal insulin \pm metformin) and allowed a significantly greater proportion of patients to achieve target $\mathrm{HbA}_{1 \mathrm{c}}$ levels [20].

Given the number of treatment options available for the management of $\mathrm{T} 2 \mathrm{D}$, it is important for decision makers to understand the relative clinical benefits of all treatment options to allow for an informed treatment decision. So far, no head-to-head trials between once-weekly semaglutide and other GLP-1 RAs in patients inadequately controlled on basal insulin ( \pm OADs) have been conducted. As each GLP-1 RA may demonstrate unique advantages and disadvantages, it is important to understand the relative efficacy and safety of each GLP-1 RA [23]. The aim of the current study was to conduct a systematic literature review (SLR) and network meta-analysis (NMA) to assess the relative efficacies and safety of GLP-1 RAs as an add-on to basal insulin ( \pm OADs) in the treatment of T2D.

\section{METHODS}

The trials included across the analyses were derived from a SLR, for which the methodology 
has been reported in Witkowski et al. [24] (while the search strategy and PICOS criteria have been previously presented in the sister publication within this journal, they are replicated in Tables S1 and Table S2 of the Electronic supplementary material, ESM, for convenience). Briefly, searches of databases (MEDLINE $^{\circledR}$, Embase, and the Cochrane Library; see Table S1 of the ESM) and conference proceedings were performed via Ovid on April 5, 2016 (updated in October 3, 2016 and August 16, 2017). Studies were then screened independently by two reviewers against the PICOS (population, interventions, comparators, outcomes, study design) selection criteria for inclusion in the SLR (Table S2 of the ESM).

An NMA was performed to compare the efficacy and safety of GLP-1 RAs in patients with T2D. In the analysis, the primary intervention of interest was once-weekly semaglutide $(0.5 \mathrm{mg}$ and $1.0 \mathrm{mg}$ ) and the primary comparators of interest were all other licensed doses of GLP-1 RAs approved for the treatment of T2D-liraglutide once-daily (QD), dulaglutide once-weekly $(\mathrm{QW})$, exenatide twice-daily (BID), exenatide QW, lixisenatide QD, and albiglutide QW; despite a withdrawal notice, albiglutide is included as the reason for withdrawal was not related to the safety of the medicine [25]. In order to reduce variability between the populations across the different trials, the definition of the add-on to basal insulin population was aligned as closely as possible with the population included in SUSTAIN 5-patients inadequately controlled on basal insulin (100\% received basal insulin) with or without metformin (approximately 83\% of patients also received metformin). As relatively few trials have been conducted in patients inadequately controlled on basal insulin \pm metformin, trials with patients inadequately controlled on basal insulin with up to two OADs were included for feasibility assessment. All trials identified in the SLR were examined for data on at least one outcome of interest, and the ability to form a best-case connected network was assessed. The feasibility of generating evidence networks for each of the 20 outcomes of interest outlined in the PICOS criteria of the SLR (Table S2 of the ESM) was then examined. All studies included in the NMA were assessed for risk of bias using a seven-criteria checklist as approved by the National Institute of Health and Care Excellence (NICE) [26].

\section{Statistical Analysis}

As previously described in the sister publication, analyses of continuous outcomes (using a normal likelihood, identity link, shared parameter model) and dichotomous outcomes (using a binomial likelihood [assuming a normal distribution], logit link model) considered feasible for assessment were implemented on WinBUGS (MRC Biostatistics Unit, Cambridge, UK [27]) using a Bayesian framework with the inclusion of vague prior distributions, and three Markov Monte Carlo chains. Both fixed-effects (FE) and random-effects (RE) models were run for each outcome and the model with the best fit (based on the deviance information criterion [DIC] and the average posterior residual deviance) was used. All NMAs were formally assessed for inconsistency using Bucher's method (as outlined by the NICE Technical Support Document 4) [28]; briefly, the inconsistency assessment with Bucher's method compares direct and indirect (NMA) estimates, and the difference between these estimates is a measure of inconsistency.

Model convergence (assessed using standard diagnostic methods for evaluating convergence) inferences were made from data obtained by sampling for a further 20,000 iterations using all the samples. If models failed to converge, the feasibility of a Bucher indirect comparison was considered. Bucher indirect comparisons were calculated in STATA 13 (release 13, 2013; StataCorp. LP, College Station, TX, USA) using the "indirect" command [29]. The results of the NMA are presented as mean treatment differences or odds ratios (ORs) and an associated 95\% credible interval (CrI). Unless the CrI excludes the null value (for treatment differences) or 1 (for ORs), it is assumed that there is no difference. Two ranking outcomes, median rank and the surface under the cumulative ranking curve (SUCRA), are also presented.

Finally, this article does not contain any new studies with human or animal subjects performed by any of the authors. 


\section{RESULTS}

\section{Identified Publications}

A total of 107 publications reporting on 75 unique trials were included within the SLR (Table S3 of the ESM) as demonstrated in the sister article within this journal; the PRISMA diagram is replicated in Fig. S1 of the ESM. Of these 75 trials, 12 trials were considered to be relevant for inclusion in the current analysis [20, 30-40]. All 12 trials considered in the NMA formed a connected network. It should be noted that the insulin lispro arms from Diamant et al. [32] and HARMONY-6 [39] were deemed to be similar enough to combine into a single treatment node. The 12 trials were next examined for time points for which data were available for at least one outcome (Fig. S2 in the ESM). All 12 trials $(100 \%)$ reported on an at least one outcome of interest between 20 and 28 weeks. Based on this, it was decided to analyze each outcome at $24 \pm 4$ weeks (approximately 6 months) of treatment-it was assumed that the level of response to treatment within 4 weeks of the target week was unlikely to vary considerably. Overall, the majority of trials (75\%) reported at either 24 or 26 weeks (range week 23-28) in the analysis at $24 \pm 4$ weeks.

The study design and patient characteristics of 12 trials are presented in Table 1 . Overall, the risk of bias across the 12 studies was considered to be low; however, the highest risk of bias across the studies was associated with elements of study blinding and omissions (Figure S3 in the ESM). In total, eight trials were deemed sufficiently homogeneous to combine for analysis, while four studies were identified as potential outliers due to study design and patient characteristics: the GetGoal-Duo 1 trial [33] screened patients who were newly initiated on basal insulin and were only included in the study if they were uncontrolled after 12 weeks; the GetGoal-O trial [38] was conducted exclusively in elderly patients; and both the GetGoalL-C trial [37] and the GetGoal L-Asia trial [36] were conducted primarily (> 85\%) in an Asian population (GLP-1 RAs are known to be more effective in Asian patients than in Caucasian patients, which may influence the relative treatment effects [41]). It was therefore decided that these studies should be excluded from the base-case analysis in order to limit the clinical heterogeneity of the NMA, yielding a total of eight studies; however, the impact of excluding those trials was to be explored in sensitivity analyses.

\section{NMA Results}

For the analysis, outcome-specific evidence networks were possible for 10 of the 20 outcomes of interest assessed for feasibility; note that it was not feasible to perform an analysis of the incidence of hypoglycemia as no connected network could be formed. Of the eight trials considered in the base-case analysis, all trials reported data on the change from baseline in $\mathrm{HbA}_{1 \mathrm{c}}$, the proportion of patients achieving $\mathrm{HbA}_{1 \mathrm{c}}<7 \%$ and $\leq 6.5 \%$, fasting plasma glucose (FPG), weight, and the incidence of nausea, vomiting, and diarrhea; only two trials (LIRAADD2BASAL [40] and SUSTAIN 5 [20]) reported the change from baseline in systolic blood pressure (SBP), and three trials (GetGoal-Duo 2 [34], GetGoal-L [35], and SUSTAIN 5 [20]) reported the proportion of patients achieving $\geq 5 \%$ weight loss. The evidence networks are shown in Fig. 1.

The FE model was preferred for all outcomes analyzed in the base case; no important differences between the $\mathrm{FE}$ and $\mathrm{RE}$ models were observed in terms of DIC and average posterior residual deviance (Table S4 of the ESM). However, the NMA for the change from baseline in SBP was unstable and failed to converge. As outlined in the methodology, a Bucher indirect comparison was therefore performed for this outcome.

The results of the NMA are presented as treatment differences or ORs (once-weekly semaglutide vs comparator) in Fig. $2 \mathrm{a}-\mathrm{h}$ (the full matrix of relative treatment effects results are shown in Tables S12-S20 of the ESM). The associated treatment ranks (SUCRA and median rank) are presented, where available, in Tables 2 and 3. 


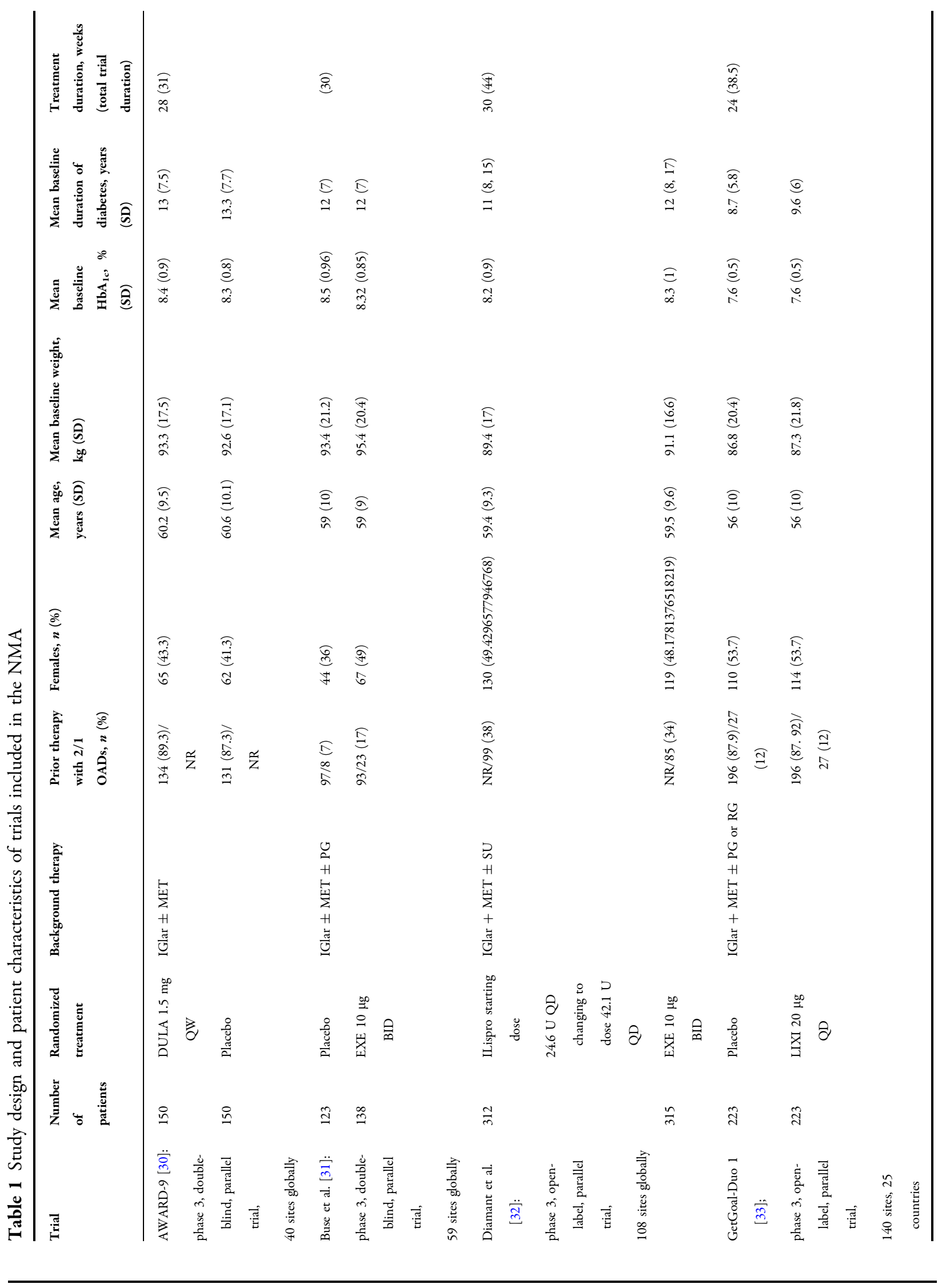




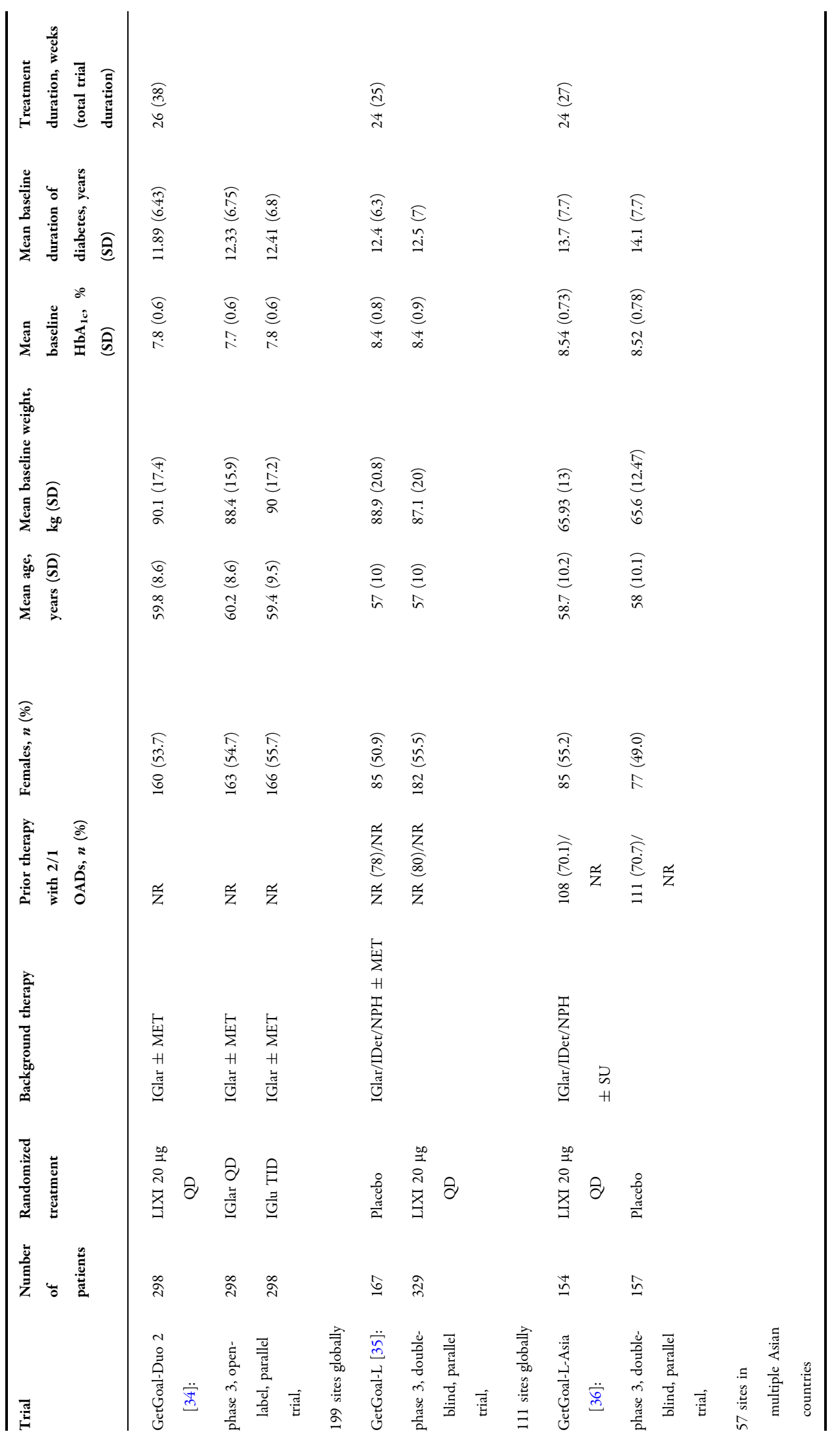




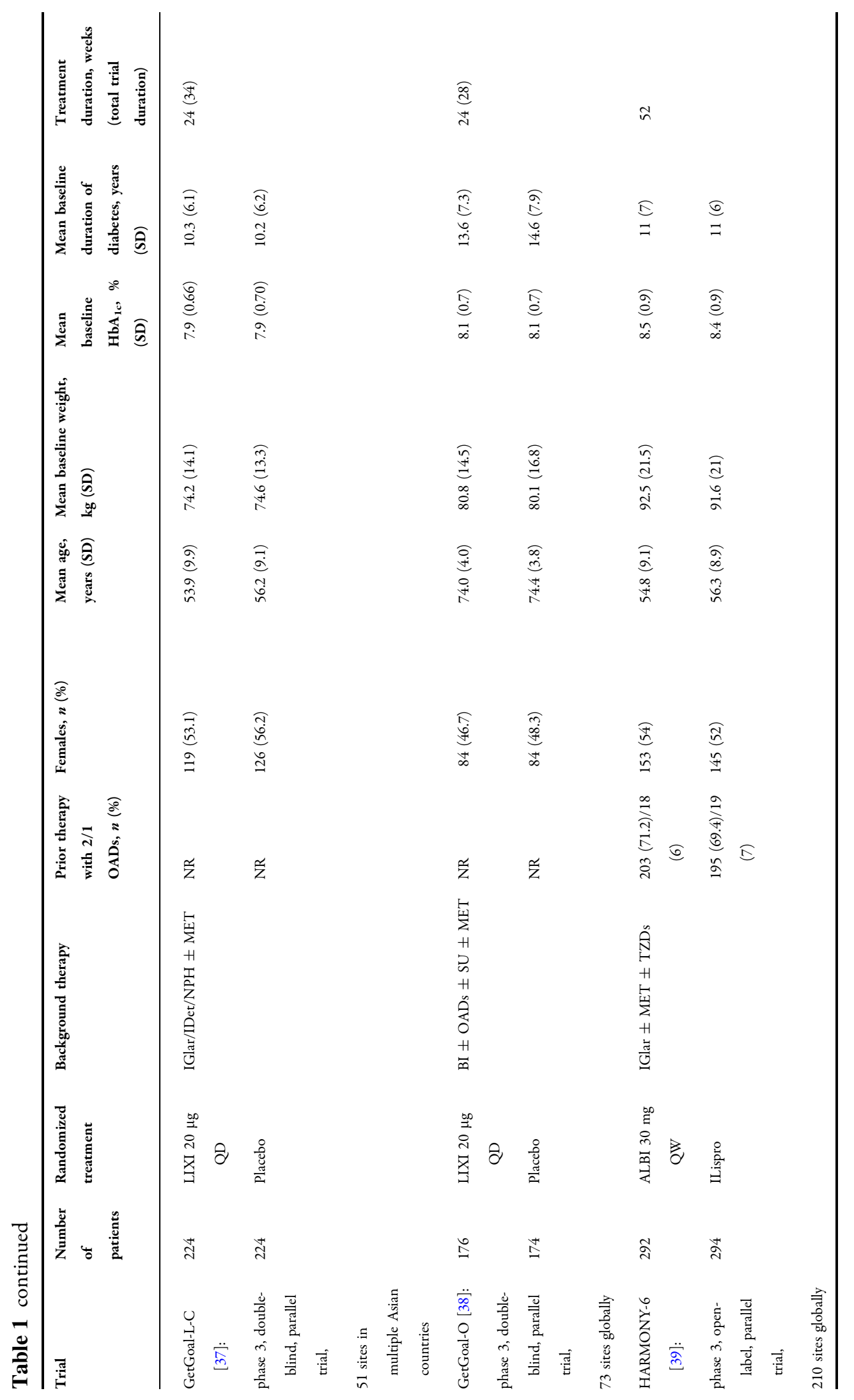




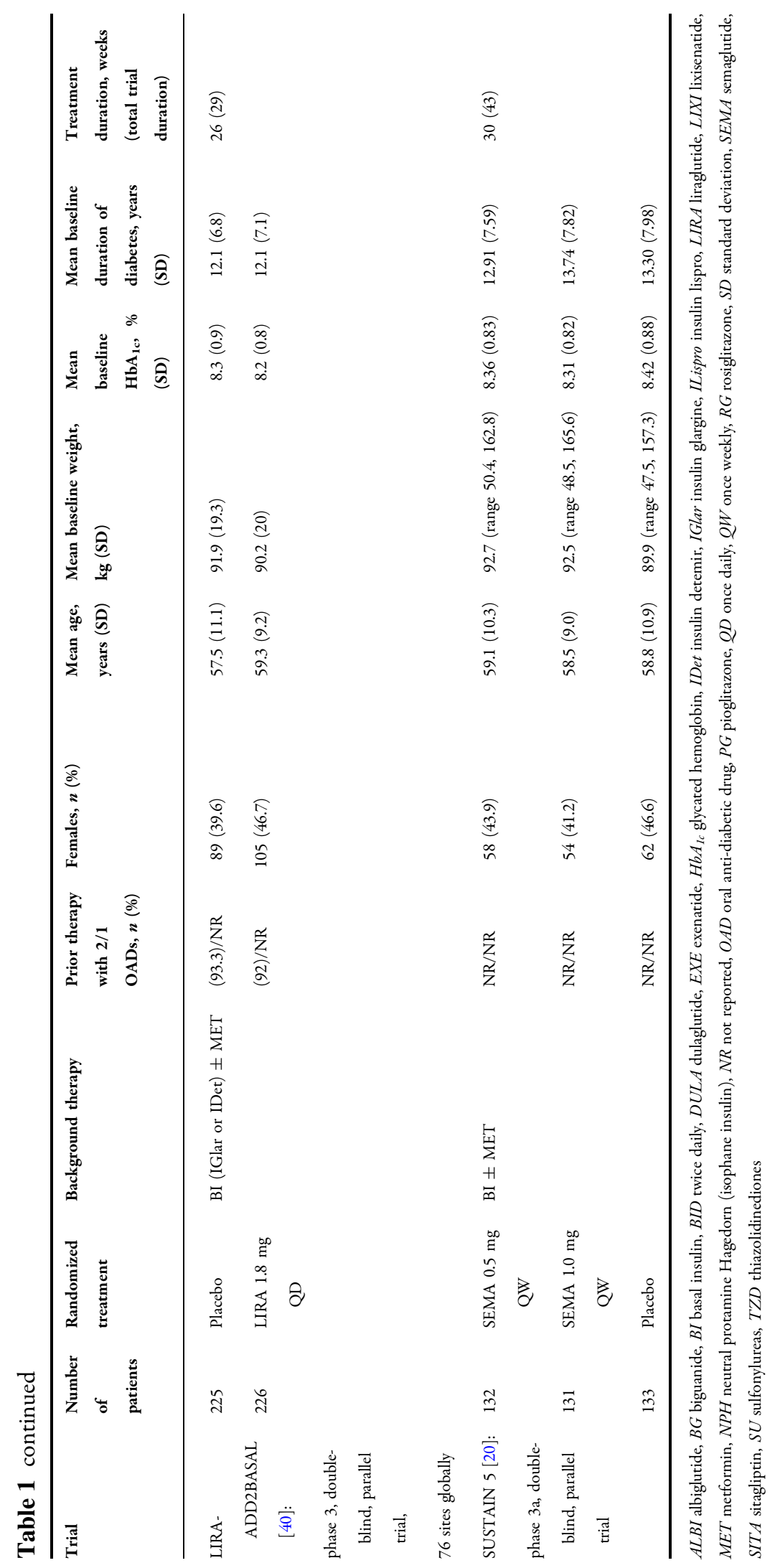



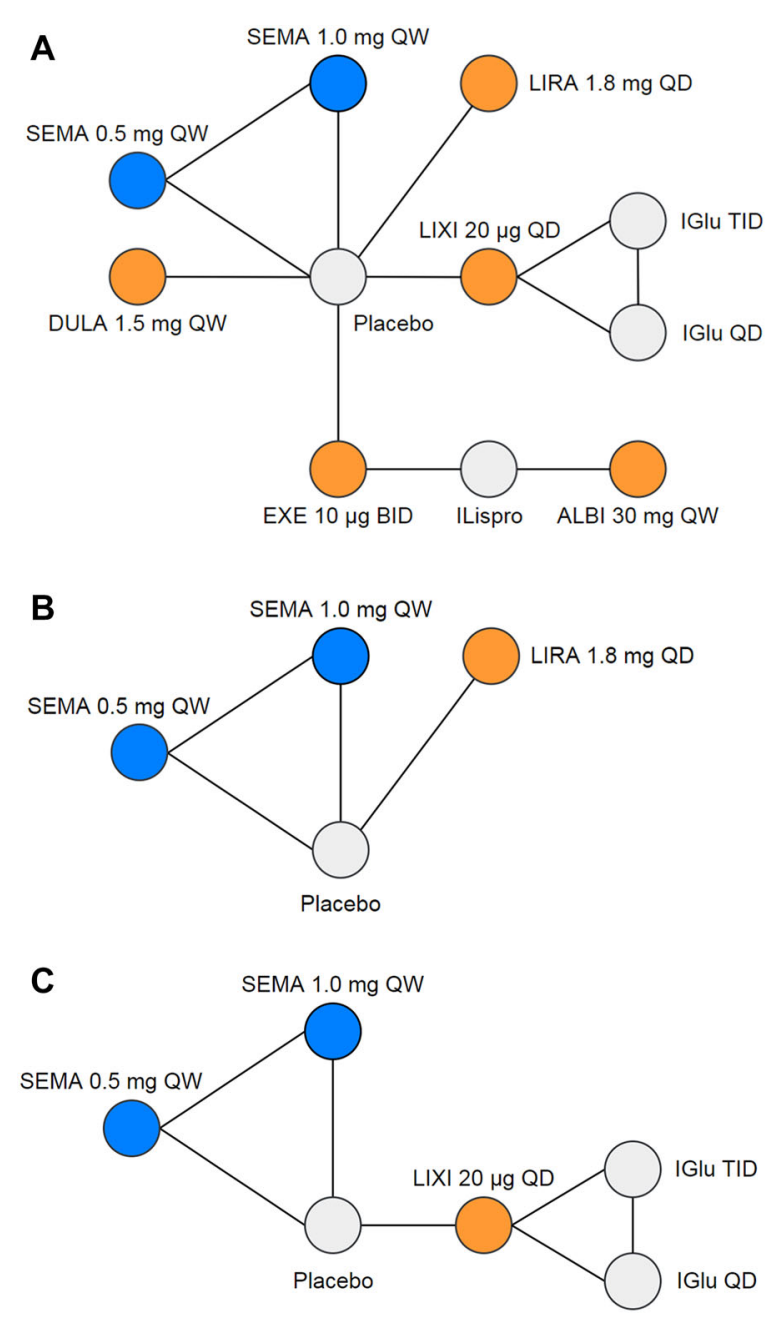

Fig. 1 Evidence networks for all outcomes. Blue nodes indicate a primary intervention of interest, orange nodes indicate a primary comparator of interest, and gray nodes indicate a secondary comparator. a The evidence network for the change from baseline in $\mathrm{HbA}_{1 \mathrm{c}}$, weight, and FPG, the proportions of patients with $\mathrm{HbA}_{1 \mathrm{c}}<7 \%$ or $\leq 6.5 \%$, and the incidence of nausea, vomiting, and diarrhea. $\mathbf{b}$ The evidence network for the change from baseline in SBP. c The evidence network for the proportion of patients with $\geq 5 \%$ weight loss. $A L B I$ albiglutide, BID twice-daily, $D U L A$ dulaglutide, EXE exenatide, IGlu insulin glulisine, ILispro insulin lispro, LIRA liraglutide, LIXI lixisenatide, $Q D$ once-daily, $Q W$ once-weekly, $S E M A$ semaglutide, $T I D$ thrice-daily

\section{Glycemic Control}

All eight trials considered in the base-case analysis reported data on the change from baseline in $\mathrm{HbA}_{1 \mathrm{c}}$ (Table S5 of the ESM). The evidence network for the change from baseline in $\mathrm{HbA}_{1 \mathrm{c}}$ is shown in Fig. 1a. Once-weekly semaglutide $1.0 \mathrm{mg}$ was associated with a significantly greater reduction in $\mathrm{HbA}_{1 \mathrm{c}}$ vs all GLP1 RA comparators included in the analysis (Fig. 2a, Table S12 of the ESM). Furthermore, based on the 0.3 percentage-points margin for clinical superiority suggested by the FDA [42] and European Medicines Agency (EMA; [43]), the improvements in $\mathrm{HbA}_{1 \mathrm{c}}$ achieved with once-weekly semaglutide $1.0 \mathrm{mg}$ were clinically meaningful vs all primary comparators. The analysis also suggested that once-weekly semaglutide $0.5 \mathrm{mg}$ can provide significantly greater reductions in $\mathrm{HbA}_{1 \mathrm{c}}$ vs all GLP-1 RA comparators except liraglutide $1.8 \mathrm{mg}$ QD. An additional sensitivity analysis using the same statistical approach as in the base-case analysis was performed to validate the legitimacy of excluding four trials [33, 36-38] from the basecase analysis on the basis of heterogeneity. The evidence network for the sensitivity analysis is shown in Fig. S4 of the ESM. The results of the analysis demonstrate that the inclusion of the outlier trials had little impact on the results and the overall interpretation of the analysis (Table S21 of the ESM).

NMAs were also feasible for the proportion of patients with $\mathrm{HbA}_{1 \mathrm{c}}$ levels $<7 \%$ or $\mathrm{HbA}_{1 \mathrm{c}}$ level $\leq 6.5 \%$ using the same evidence network as shown in Fig. 1a. Data supporting these analyses are shown in Table S6 of the ESM. In line with the results seen for change from baseline in $\mathrm{HbA}_{1 \mathrm{c}}$, analysis of the proportion of patients achieving $\mathrm{HbA}_{1 \mathrm{c}}$ targets showed that onceweekly semaglutide $1.0 \mathrm{mg}$ had significantly higher odds of achieving a $\mathrm{HbA}_{1 \mathrm{c}}$ level $<7 \%$ vs all GLP-1 RA comparators (Fig. 2b, Table S13 of the ESM). Once-weekly semaglutide $0.5 \mathrm{mg}$ also demonstrated significantly higher odds of achieving a $\mathrm{HbA}_{1 \mathrm{c}}$ level $<7 \%$ vs all GLP-1 RA comparators, except liraglutide $1.8 \mathrm{mg} \mathrm{QD}$, to which it was comparable. Once-weekly semaglutide $1.0 \mathrm{mg}$ had higher odds of achieving a $\mathrm{HbA}_{1 \mathrm{c}}$ level $\leq 6.5 \%$ vs the majority of GLP1 RA comparators, except liraglutide $1.8 \mathrm{mg}$, to which it was comparable; once-weekly semaglutide $0.5 \mathrm{mg}$ had similar odds vs all GLP1 RA comparators (Fig. 2c, Table S14 of the ESM). 
A

Once-weekly semaglutide $1.0 \mathrm{mg}$ vs comparators

Treatment difference: $\mathrm{HbA}_{1 \mathrm{c}}, \%(95 \% \mathrm{Crl})$
Once-weekly semaglutide $0.5 \mathrm{mg}$ vs comparators

Treatment difference: $\mathrm{HbA}_{1 \mathrm{c}}, \%(95 \% \mathrm{Crl})$

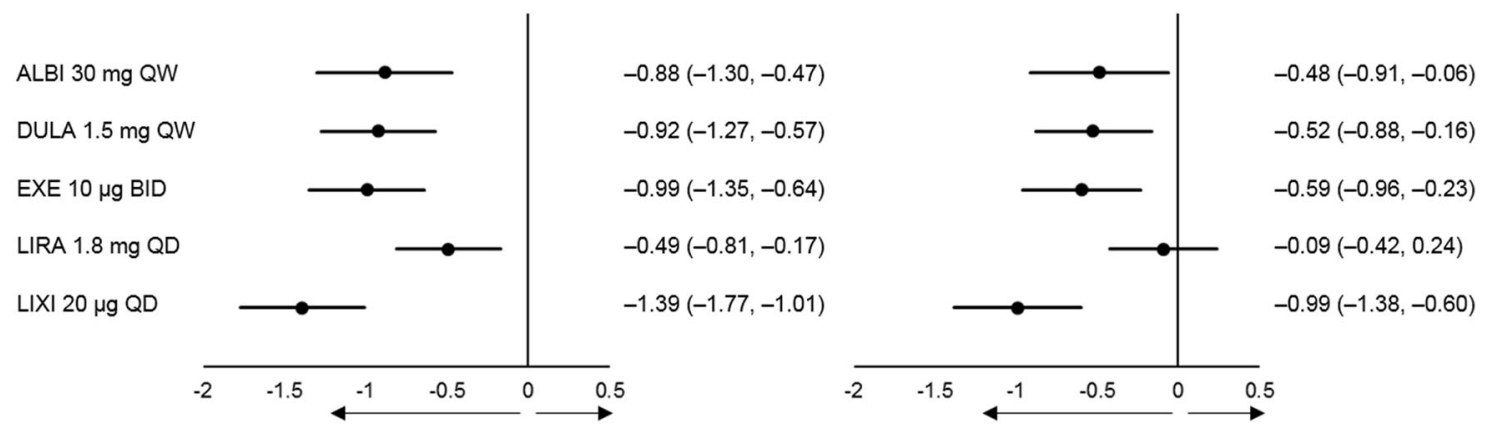

Favors once-weekly semaglutide $1.0 \mathrm{mg}$ Favors comparator Favors once-weekly semaglutide $0.5 \mathrm{mg}$ Favors comparator

B

Once-weekly semaglutide $1.0 \mathrm{mg}$ vs comparators $\mathrm{HbA}_{1 \mathrm{c}}<7 \%$ : Odds ratio $(95 \% \mathrm{Crl})$

ALBI $30 \mathrm{mg}$ QW

DULA $1.5 \mathrm{mg}$ QW

EXE $10 \mu \mathrm{g}$ BID

LIRA $1.8 \mathrm{mg}$ QD

LIXI $20 \mu \mathrm{g} Q D$

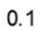

Favors comparator Favors once-weekly semaglutide $1.0 \mathrm{mg}$

C

Once-weekly semaglutide $1.0 \mathrm{mg}$ vs comparators

$\mathrm{HbA}_{1 \mathrm{c}} \leq 6.5 \%$ : Odds ratio $(95 \% \mathrm{Crl})$

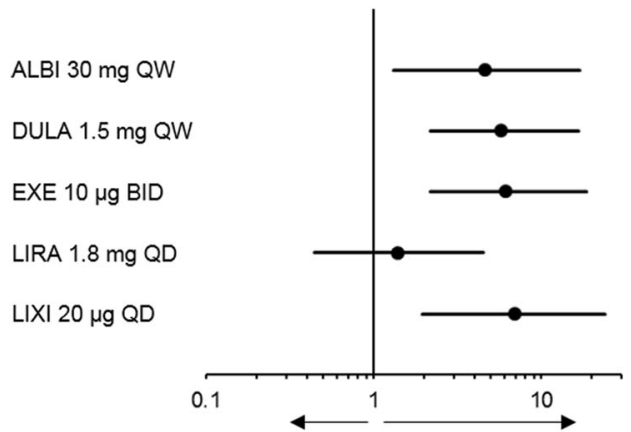

$4.63(1.32,16.95)$

$5.78(2.19,16.67)$

$6.16(2.18,18.69)$

$1.39(0.44,4.47)$

$6.93(1.96,23.87)$

Favors comparator Favors once-weekly semaglutide $1.0 \mathrm{mg}$
Once-weekly semaglutide $\mathbf{0 . 5} \mathrm{mg}$ vs comparators $\mathrm{HbA}_{1 \mathrm{c}}<7 \%$ : Odds ratio $(95 \% \mathrm{Crl})$

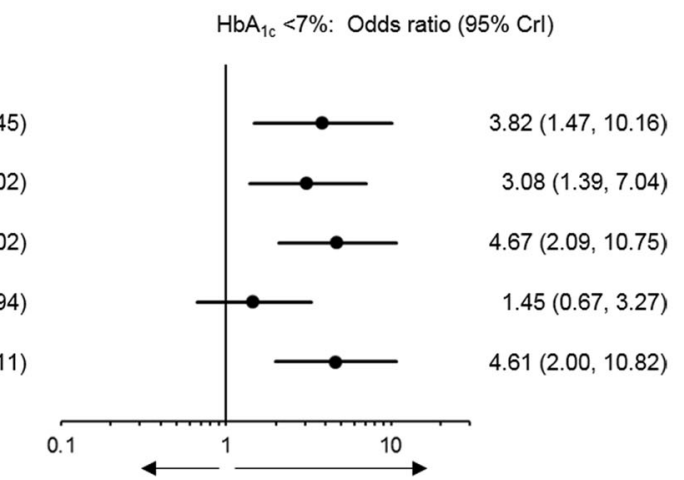

Favors comparator Favors once-weekly semaglutide $0.5 \mathrm{mg}$

Once-weekly semaglutide $0.5 \mathrm{mg}$ vs comparators $\mathrm{HbA}_{1 \mathrm{c}} \leq 6.5 \%$ : Odds ratio $(95 \% \mathrm{Crl})$

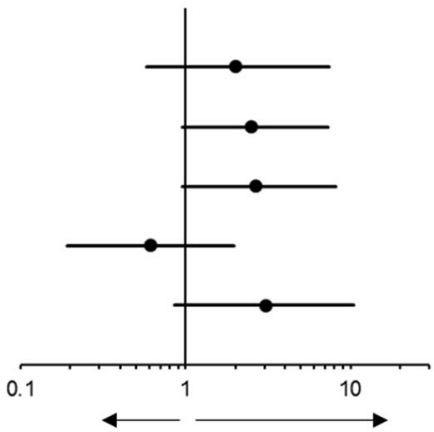

$2.03(0.58,7.43)$

$2.53(0.96,7.29)$

$2.70(0.96,8.17)$

$0.61(0.19,1.95)$

$3.04(0.86,10.47)$
Fig. 2 Forest plots of the NMA results-once-weekly semaglutide 0.5 or $1.0 \mathrm{mg}$ vs comparator. Treatment differences are considered significant when the $95 \% \mathrm{CrI}$ excludes the null value. Odds ratios are considered significant when the 95\% CrI excludes 1. The NMA results are presented as Forest plots for a change from baseline in $\mathrm{HbA}_{1 \mathrm{c}}$, b proportion of patients achieving target $\mathrm{HbA}_{1 \mathrm{c}}<7 \%$ or $\mathbf{c} \mathrm{HbA}_{1 \mathrm{c}} \leq 6.5 \%$, $\mathbf{d}$ change from baseline in FPG, e change from baseline in weight, and the incidence of $\mathbf{f}$ nausea, $\mathbf{g}$ vomiting, and $\mathbf{h}$ diarrhea. $A L B I$ albiglutide, $B I D$ twice-daily, $C r I$ credible interval, $D U L A$ dulaglutide, $E X E$ exenatide, $F P G$ fasting plasma glucose, $H b A_{\text {Ic }}$ glycated hemoglobin, LIRA liraglutide, LIXI lixisenatide, $N M A$ network meta-analysis, $Q D$ once-daily, $Q W$ once-weekly 


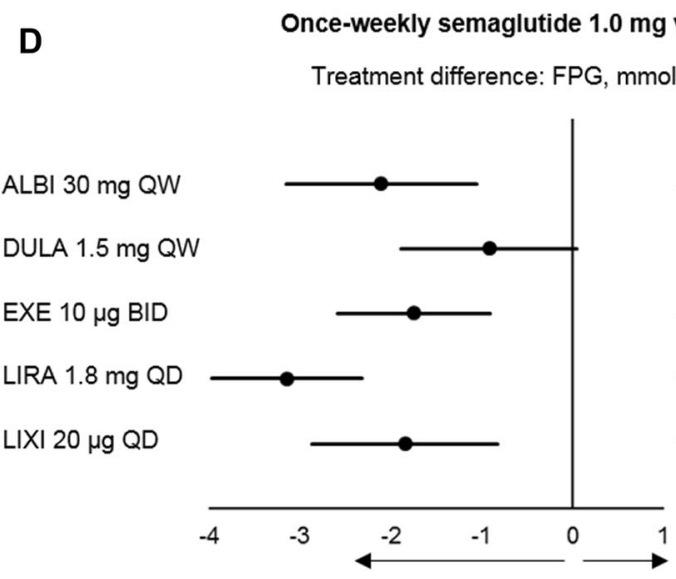

Favors once-weekly semaglutide $1.0 \mathrm{mg}$ Favors comparator

E

Once-weekly semaglutide $1.0 \mathrm{mg}$ vs comparators

Treatment difference: weight, $\mathrm{kg}(95 \% \mathrm{Crl})$
$-2.10(-3.15,-1.06)$

$-0.91(-1.88,0.05)$

$-1.74(-2.58,-0.91)$

$-3.14(-3.97,-2.32)$

$-1.84(-2.86,-0.82)$
Once-weekly semaglutide $\mathbf{0 . 5} \mathrm{mg}$ vs comparators

Treatment difference: FPG, mmol/L $(95 \% \mathrm{Crl})$

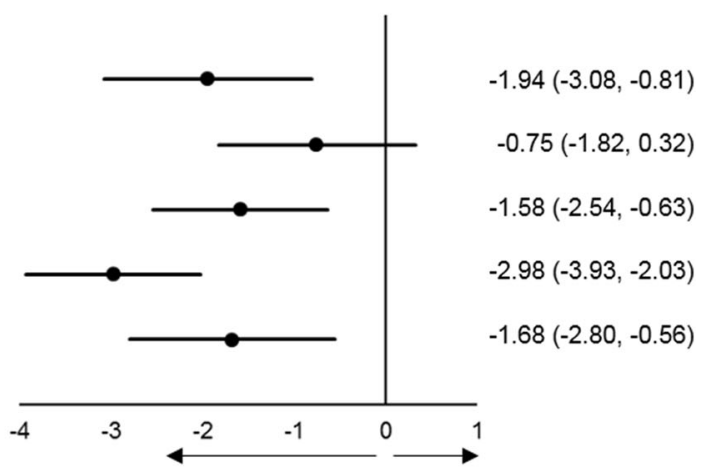

Favors once-weekly semaglutide $0.5 \mathrm{mg}$ Favors comparator

Once-weekly semaglutide $0.5 \mathrm{mg}$ vs comparators

Treatment difference: weight, $\mathrm{kg}(95 \% \mathrm{Crl})$

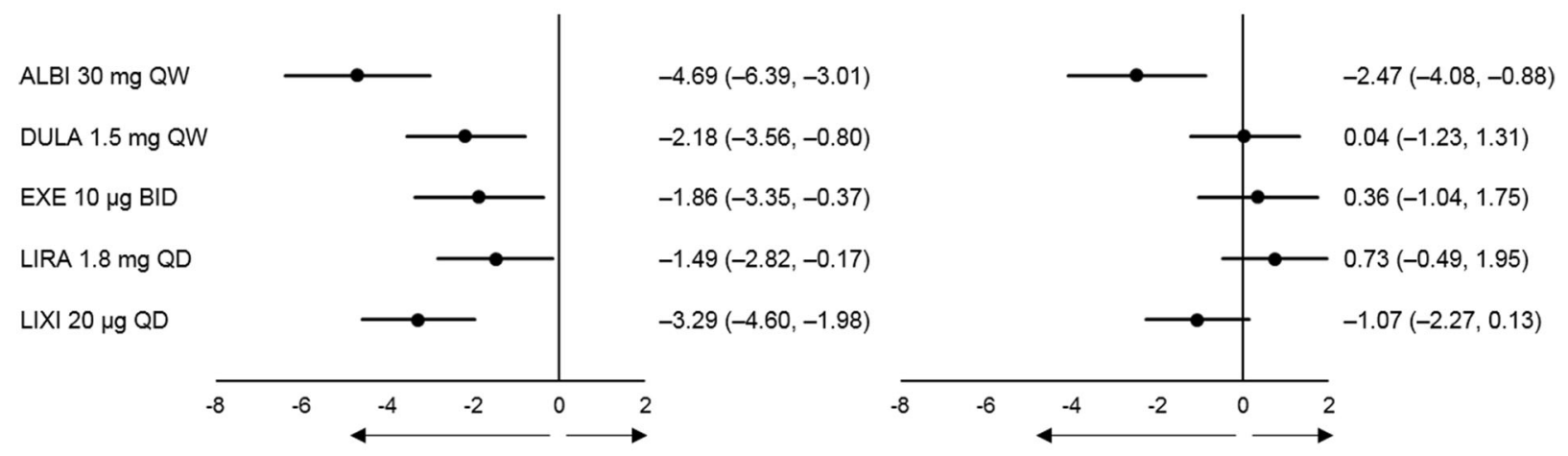

Favors once-weekly semaglutide $1.0 \mathrm{mg}$ Favors comparator

Favors once-weekly semaglutide $0.5 \mathrm{mg}$ Favors comparator

F

Once-weekly semaglutide $1.0 \mathrm{mg}$ vs comparators

Nausea: Odds ratio $(95 \% \mathrm{Crl})$
Once-weekly semaglutide $0.5 \mathrm{mg}$ vs comparators

Nausea: Odds ratio $(95 \% \mathrm{Crl})$

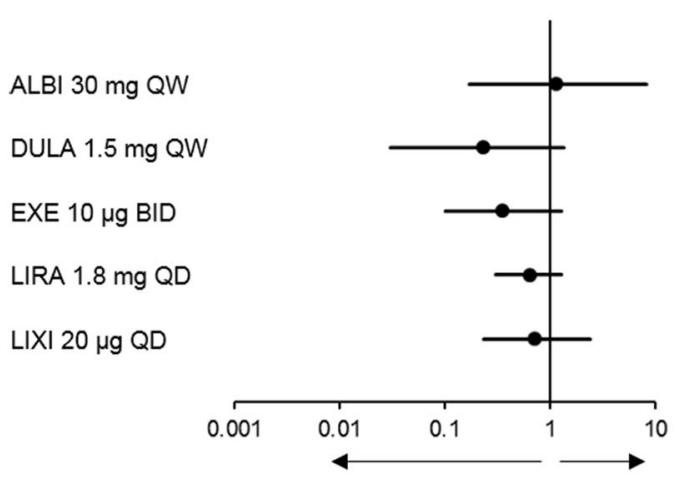

Favors once-weekly semaglutide $1.0 \mathrm{mg}$ Favors comparator
$1.16(0.17,8.08)$

$0.23(0.03,1.33)$

$0.35(0.10,1.28)$

$0.63(0.30,1.27)$

$0.71(0.23,2.41)$

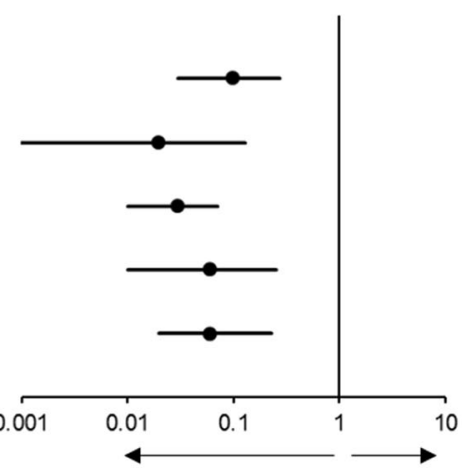

Favors once-weekly semaglutide $0.5 \mathrm{mg}$ Favors comparator

Fig. 2 continued 
G

Once-weekly semaglutide $1.0 \mathrm{mg}$ vs comparators

Vomiting: Odds ratio $(95 \% \mathrm{Crl})$
Once-weekly semaglutide $0.5 \mathrm{mg}$ vs comparators

Vomiting: Odds ratio $(95 \% \mathrm{Crl})$

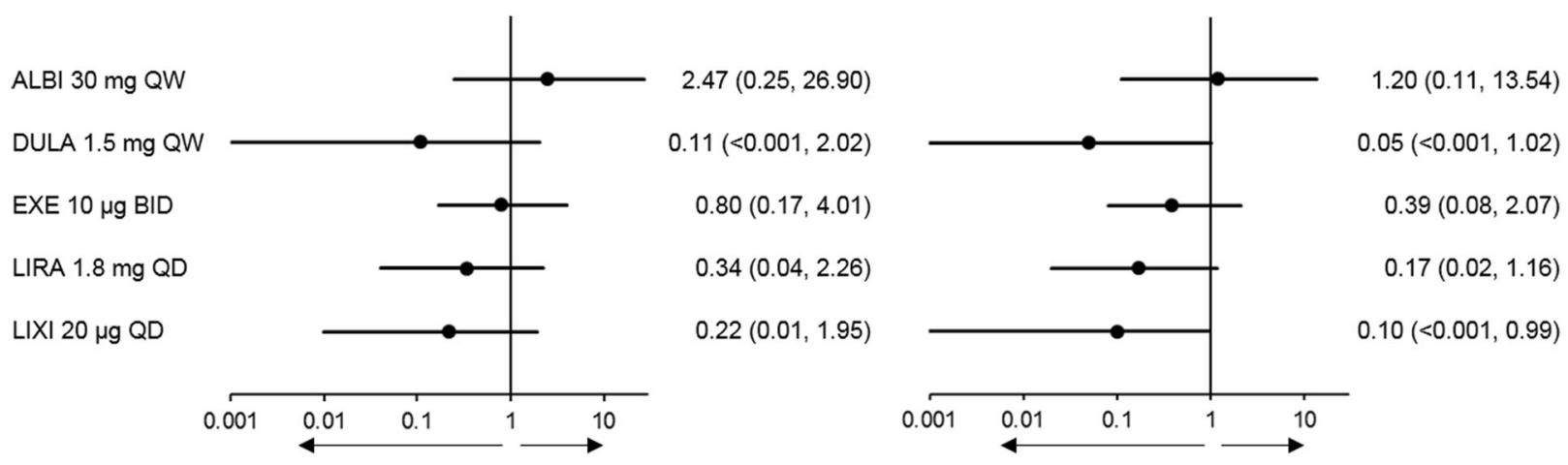

Favors once-weekly semaglutide $1.0 \mathrm{mg}$ Favors comparator

Favors once-weekly semaglutide $0.5 \mathrm{mg}$ Favors comparator

H

Once-weekly semaglutide $1.0 \mathrm{mg}$ vs comparators

Diarrhea: Odds ratio $(95 \% \mathrm{Crl})$

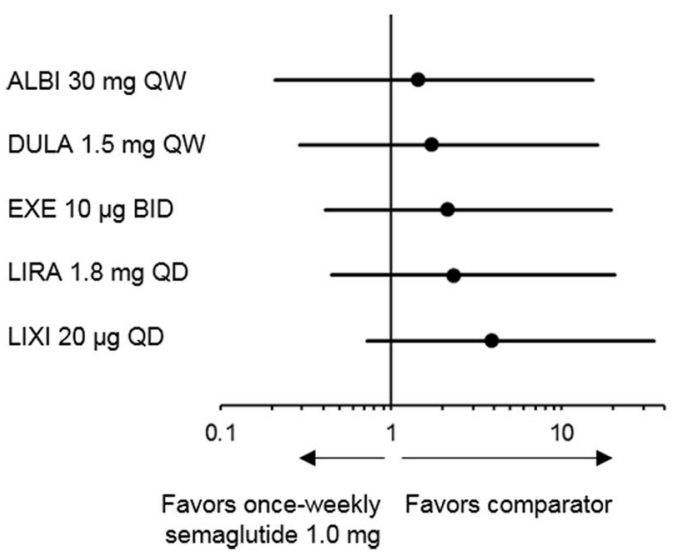

Fig. 2 continued

A NMA was also performed for FPG using the same evidence network as shown in Fig. 1a (Table S7 of the ESM). In line with the results achieved relating to reductions in $\mathrm{HbA}_{1 \mathrm{c}}$, the analysis of the change from baseline in FPG demonstrated that once-weekly semaglutide $1.0 \mathrm{mg}$ and $0.5 \mathrm{mg}$ were both associated with significantly greater reductions in FPG compared with the majority of GLP-1 RA comparators, except dulaglutide $1.5 \mathrm{mg}$, to which they were comparable (Fig. 2d, Table S15 of the ESM).

Across these analyses, once-weekly semaglutide $1.0 \mathrm{mg}$ was the highest ranked GLP-1 RA, achieving a median rank of 1 and a SUCRA score of $100 \%$ across all glycemic outcomes (Tables 2 ,
3). In line with the interpretation of SUCRA scores [44], this indicates that once-weekly semaglutide $1.0 \mathrm{mg}$ is the most efficacious treatment within these networks. Despite the absence of lower-dose variants of the GLP-1 RA comparators from the analyses (e.g., dulaglutide $0.75 \mathrm{mg}$ QW, exenatide $5 \mu \mathrm{g}$ BID), once-weekly semaglutide $0.5 \mathrm{mg}$ ranked highly in the analysis of these glycemic outcomes, achieving median ranks of 2-3 and SUCRA scores of 80-90\% (Tables 2, 3).

\section{Weight}

All eight trials included in the base-case analysis reported data for the change from baseline in body weight (Table S8 of the ESM). The 
Table 2 SUCRA results

\begin{tabular}{|c|c|c|c|c|c|c|c|c|c|}
\hline Comparator & $\begin{array}{c}\text { CFB in } \mathrm{HbA}_{\mathrm{lc}} \\
(\%)\end{array}$ & $\begin{array}{c}\mathrm{HbA}_{1 \mathrm{c}}<7 \% \\
(\%)\end{array}$ & $\begin{array}{c}\mathrm{HbA}_{\mathrm{lc}} \leq 6.5 \% \\
(\%)\end{array}$ & $\begin{array}{c}\text { CFB in FPG } \\
(\%)\end{array}$ & $\begin{array}{c}\text { CFB in weight } \\
(\%)\end{array}$ & $\begin{array}{c}\geq 5 \% \text { weight loss } \\
\text { (\%) }\end{array}$ & Nausea (\%) & Vomiting (\%) & Diarrhea (\%) \\
\hline Semaglutide $0.5 \mathrm{mg} \mathrm{QW}$ & 90 & 90 & 80 & 90 & 70 & 80 & 80 & 70 & 20 \\
\hline Semaglutide $1.0 \mathrm{mg} \mathrm{QW}$ & 100 & 100 & 100 & 100 & 100 & 100 & 50 & 50 & 10 \\
\hline Albiglutide $30 \mathrm{mg} \mathrm{QW}$ & 70 & 50 & 60 & 20 & 30 & & 60 & 70 & 20 \\
\hline Dulaglutide $1.5 \mathrm{mg} \mathrm{QW}$ & 60 & 60 & 40 & 80 & 70 & & 0 & 0 & 30 \\
\hline Exenatide $10 \mu \mathrm{g}$ BID & 50 & 30 & 40 & 60 & 80 & & 20 & 40 & 40 \\
\hline Insulin glulisine $\mathrm{QD}^{\mathrm{a}}$ & 20 & 20 & 20 & 50 & 20 & 40 & 90 & 60 & 90 \\
\hline Insulin glulisine TID $^{\mathrm{a}}$ & 30 & 60 & 70 & 40 & 10 & 0 & 100 & 50 & 100 \\
\hline Insulin lispro ${ }^{\mathrm{a}}$ & 40 & 30 & 30 & 10 & 0 & & 10 & 100 & 70 \\
\hline Liraglutide $1.8 \mathrm{mg}$ & 80 & 80 & 90 & 0 & 90 & & 30 & 20 & 40 \\
\hline Lixisenatide $20 \mu \mathrm{g}$ QD & 20 & 30 & 30 & 50 & 50 & 60 & 40 & 10 & 60 \\
\hline Placebo $^{a}$ & 0 & 0 & 0 & 50 & 30 & 20 & 70 & 90 & 80 \\
\hline
\end{tabular}

The highest and second highest SUCRA values of the primary comparators per outcome are highlighted in green and blue, respectively. The calculation of SUCRA scores for the change from baseline in SBP was not possible as the analysis was performed via a Bucher indirect comparison only

$B I D$ twice-daily, $C F B$ change from baseline, $C r I$ credible interval, $F P G$ fasting plasma glucose, $H b A_{1 c}$ glycated hemoglobin, $Q D$ once-daily, $Q W$ once-weekly, $S B P$ systolic blood pressure, SUCRA surface under the cumulative ranking, TID thricedaily

a Secondary comparators

Table 3 Median ranks

\begin{tabular}{|c|c|c|c|c|c|c|c|c|c|}
\hline Comparator & CFB in $\mathrm{HbA}_{\mathrm{lc}}$ & $\mathrm{HbA}_{\mathrm{lc}}<7 \%$ & $\mathrm{HbA}_{\mathrm{Ic}} \leq 6.5 \%$ & CFB in FPG & CFB in weight & $\begin{array}{c}\geq 5 \% \text { weight } \\
\text { loss }\end{array}$ & Nausea & Vomiting & Diarrhea \\
\hline Semaglutide $0.5 \mathrm{mg}$ QW & $2(2,3)$ & $2(2,3)$ & $3(2,7)$ & $2(1,3)$ & $4(2,6)$ & $2(2,4)$ & $3(1,3)$ & $4(2,8)$ & $9(3,11)$ \\
\hline Semaglutide $1.0 \mathrm{mg} \mathrm{QW}$ & $1(1,1)$ & $1(1,1)$ & $1(1,2)$ & $1(1,2)$ & $1(1,1)$ & $1(1,2)$ & $6(5,9)$ & $6(4,10)$ & $10(5,11)$ \\
\hline Albiglutide $30 \mathrm{mg} \mathrm{QW}$ & $4(3,7)$ & $6(4,10)$ & $5(3,10)$ & $9(4,10)$ & $8(6,10)$ & & $5(4,10)$ & $4(2,9)$ & $9(5,11)$ \\
\hline Dulaglutide $1.5 \mathrm{mg} \mathrm{QW}$ & $5(4,8)$ & $5(4,9)$ & $7(4,10)$ & $3(2,5)$ & $4(2,5)$ & & $11(6,11)$ & $11(5,11)$ & $8(4,11)$ \\
\hline Exenatide $10 \mu \mathrm{g}$ BID & $6(4,8)$ & $8(5,10)$ & $7(4,10)$ & $5(4,8)$ & $3(2,5)$ & & $9(7,11)$ & $7(4,10)$ & $7(5,10)$ \\
\hline Insulin glulisine $\mathrm{QD}^{\mathrm{a}}$ & $9(6,11)$ & $9(5,10)$ & $9(5,10)$ & $6(4,10)$ & $9(7,10)$ & $4(4,6)$ & $2(1,3)$ & $5(1,10)$ & $2(1,6)$ \\
\hline Insulin glulisine TID ${ }^{\mathrm{a}}$ & $8(4,10)$ & $5(4,8)$ & $4(2,8)$ & $7(4,10)$ & $10(7,11)$ & $6(4,6)$ & $1(1,3)$ & $6(2,10)$ & $1(1,2)$ \\
\hline Insulin lispro ${ }^{a}$ & $7(5,10)$ & $8(5,10)$ & $8(4,10)$ & $10(6,10)$ & $11(9,11)$ & & $10(7,11)$ & $1(1,3)$ & $4(1,8)$ \\
\hline Liraglutide $1.8 \mathrm{mg}$ & $3(2,3)$ & $3(2,4)$ & $2(1,4)$ & $11(10,11)$ & $2(2,4)$ & & $8(5,11)$ & $9(5,11)$ & $7(4,11)$ \\
\hline Lixisenatide $20 \mu \mathrm{g}$ QD & $9(8,10)$ & $8(5,10)$ & $8(4,10)$ & $6(4,9)$ & $6(5,7)$ & $3(1,3)$ & $7(5,9)$ & $10(7,11)$ & $5(3,9)$ \\
\hline Placebo $^{\mathrm{a}}$ & $11(10,11)$ & $11(11,11)$ & $11(11,11)$ & $6(4,9)$ & $8(7,10)$ & $5(4,6)$ & $4(4,5)$ & $2(1,4)$ & $3(2,5)$ \\
\hline
\end{tabular}

The highest and second highest median ranks of the primary comparators per outcome are highlighted in green and blue, respectively. The calculation of median ranks for the change from baseline in SBP was not possible as the analysis was performed via a Bucher indirect comparison only

$B I D$ twice-daily, $C F B$ change from baseline, $C r I$ credible interval, $F P G$ fasting plasma glucose, $H b A_{l c}$ glycated hemoglobin, $Q D$ once-daily, $Q W$ once-weekly, $S B P$ systolic blood pressure, $T I D$ thrice-daily

${ }^{a}$ Secondary comparators

evidence network for the change in body weight was the same as for the outcomes of glycemic control presented in Fig. 1a. The results showed that once-weekly semaglutide $1.0 \mathrm{mg}$ was associated with a significantly greater reduction in body weight vs all GLP-1 
Table 4 Matrix of results for the change from baseline in SBP

\begin{tabular}{|c|c|c|c|c|}
\hline \multirow[t]{2}{*}{ Treatment A } & \multicolumn{4}{|c|}{ Treatment B } \\
\hline & Placebo & Liraglutide $1.8 \mathrm{mg}$ QD & Semaglutide $0.5 \mathrm{mg}$ QW & Semaglutide $1.0 \mathrm{mg}$ QW \\
\hline \multicolumn{5}{|l|}{ Placebo } \\
\hline Liraglutide $1.8 \mathrm{mg}$ QD & $-5.02(-7.45,-2.59)$ & & & \\
\hline Semaglutide $0.5 \mathrm{mg}$ QW & $-0.06(-3.94,3.82)$ & $4.96(0.38,9.54)^{\mathrm{a}}$ & & \\
\hline Semaglutide $1.0 \mathrm{mg} \mathrm{QW}$ & $-3.69(-7.82,0.44)$ & $1.33(-3.46,6.12)^{\mathrm{a}}$ & $-3.63(-9.30,2.04)$ & \\
\hline
\end{tabular}

Treatment difference: treatment A (row) vs treatment B (column), $\mathrm{mmHg}$ (95\% CI)

Green shaded cells indicate a significantly greater reduction (improvement) from baseline in the outcome with treatment A vs treatment $\mathrm{B}$ where the $95 \% \mathrm{CrI}$ excludes the null value

Red shaded cells indicate a significantly greater increase (worsening) from baseline in the outcome with treatment A vs treatment $\mathrm{B}$ where the $95 \% \mathrm{CrI}$ excludes the null value

$C F B$ change from baseline, $C I$ confidence interval, $Q D$ once-daily, $Q W$ once-weekly, $S B P$ systolic blood pressure

a These two estimates are indirect comparisons. All remaining estimates in this matrix are trial-level direct comparisons

RA comparators (Fig. 2e, Table S16 of the ESM). Furthermore, once-weekly semaglutide $1.0 \mathrm{mg}$ achieved a median rank of 1 and a SUCRA score of $100 \%$, indicating that this treatment is the most efficacious option for a reduction in body weight within the network (Tables 2, 3). Overall, once-weekly semaglutide $0.5 \mathrm{mg}$ was broadly comparable to all GLP-1 RA comparators. An additional sensitivity analysis, performed to validate the legitimacy of excluding four trials [33, 35-38] from the base-case analysis (Fig. S4 of the ESM), showed that the inclusion of the outlier trials had little impact on the results and interpretation of the analysis (Table S21 of the ESM). A NMA was also possible for the proportion of patients achieving $\geq 5 \%$ weight loss using data from three trials (GetGoal-Duo 2 [34], GetGoal-L [35], and SUSTAIN 5 [20]; Table S9); however, lixisenatide $20 \mu \mathrm{g}$ QD was the only GLP-1 RA available for comparison (Fig. 1c). Overall, once-weekly semaglutide $1.0 \mathrm{mg}$ and $0.5 \mathrm{mg}$ had comparable odds of achieving $\geq 5 \%$ weight loss vs lixisenatide $20 \mu \mathrm{g}$ QD (Table S17 of the ESM).

\section{Systolic Blood Pressure}

Only two trials (LIRA-ADD2BASAL [40] and SUSTAIN 5 [20]) reported data on the change from baseline in SBP and were included in an indirect comparison (Table S10 of the ESM). Therefore, only a comparison between once- weekly semaglutide and liraglutide $1.8 \mathrm{mg}$ QD was possible (Fig. 1b). This analysis suggests that the change in SBP with once-weekly semaglutide $1.0 \mathrm{mg}$ was comparable with liraglutide 1.8 $\mathrm{mg}$ in this population. In contrast, the change in SBP with liraglutide $1.8 \mathrm{mg}$ QD was more effective than once-weekly semaglutide $0.5 \mathrm{mg}$ (Table 4).

\section{Adverse Events}

It is important to consider whether the improved efficacy of once-weekly semaglutide vs other GLP-1 RA comparators is at the expense of an increase in adverse events (AEs). The most common AEs associated with the GLP-1 RA class compared with other anti-diabetic drug classes are gastrointestinal (GI)-related [45]. In this NMA, it was feasible to analyze three GI-related AEs: nausea, vomiting, and diarrhea. The data included in the base-case analysis of these outcomes are shown in Table S11 of the ESM and the evidence network (the same for each outcome) is presented in Fig. 1a. Overall, onceweekly semaglutide $1.0 \mathrm{mg}$ was associated with similar odds of nausea, vomiting, or diarrhea vs all GLP-1 RA comparators (Fig. 2f-h, Tables S18-S20 of the ESM). Once-weekly semaglutide $0.5 \mathrm{mg}$ was associated with similar odds of vomiting or diarrhea; however, the risk of nausea with once-weekly semaglutide $0.5 \mathrm{mg}$ was significantly lower vs all other GLP-1 RA comparators. 


\section{DISCUSSION}

The objective of this study was to demonstrate the efficacy and safety of once-weekly semaglutide vs other GLP-1 RAs in patients with T2D inadequately controlled on basal insulin ( \pm OADs). The analyses demonstrated that once-weekly semaglutide $1.0 \mathrm{mg}$ was associated with significantly greater reductions in $\mathrm{HbA}_{1 \mathrm{c}}$ and body weight vs all other GLP-1 RAs. This was reflected in a SUCRA score of $100 \%$, indicating that once-weekly semaglutide $1.0 \mathrm{mg}$ is the most efficacious treatment within these networks. Additional analyses showed that the significantly greater reductions in $\mathrm{HbA}_{1 \mathrm{c}}$ and body weight with once-weekly semaglutide $1.0 \mathrm{mg}$ are also supported by significant improvements in FPG and significantly higher odds of achieving the $\mathrm{HbA}_{1 \mathrm{c}}$ targets of $<7 \%$ and $\leq 6.5 \%$ compared with other GLP-1 RAs. The analyses also demonstrated that once-weekly semaglutide $0.5 \mathrm{mg}$ can provide significantly greater reductions in $\mathrm{HbA}_{1 \mathrm{c}}$ vs the majority of GLP-1 RA comparators. The increased efficacy of once-weekly semaglutide was not at the expense of reduced tolerability, as the GI-related side effects of nausea, vomiting, and diarrhea were comparable between once-weekly semaglutide and other GLP-1 RA comparators.

This is the first NMA to assess the efficacy and safety of once-weekly semaglutide as an add-on to basal insulin in patients with T2D vs other GLP-1 RAs. To our knowledge, no other study has performed a comparative analysis of GLP-1 RAs as an add-on to basal insulin; however, previous systematic reviews and meta-analyses have assessed the efficacy and safety of GLP-1 RAs compared with other anti-diabetic treatments in this population. In a systematic review of studies assessing the safety and efficacy of GLP-1 RAs (exenatide, liraglutide, lixisenatide) as an add-on to basal insulin, the majority of studies reported beneficial effects of such a combination compared with other treatment regimens [15]. In a meta-analysis comparing the efficacy and safety of a combination of GLP-1 RAs and basal insulin vs other antidiabetic treatment regimens, the combination of a GLP-1 RA and basal insulin yielded a greater mean reduction in $\mathrm{HbA}_{1 \mathrm{c}}$ and body weight by
$-0.44 \%$ and $-3.22 \mathrm{~kg}$, respectively, and a greater likelihood of patients achieving a $\mathrm{HbA}_{1 \mathrm{c}}$ level $<7 \%$ [14].

In this NMA, once-weekly semaglutide $1.0 \mathrm{mg}$ was the most clinically effective GLP-1 RA for achieving glycemic targets and reducing $\mathrm{HbA}_{1 \mathrm{c}}$, FPG, and body weight in patients who are receiving basal insulin. This was supported by SUCRA scores which indicated that onceweekly semaglutide is the most clinically efficacious in the evidence network. However, it is important that an increase in efficacy does not come at the expense of an increase in AEs. The most frequent AEs linked with GLP-1 RA therapy are GI-related (e.g., nausea, vomiting, and diarrhea); however, these AEs are thought to be dose dependent and can decline over time $[45,46]$. In a NMA investigating the relative frequencies of GI-related AEs in association with various GLP-1 RAs (excluding semaglutide), it was demonstrated that taspoglutide (now withdrawn), albiglutide and lixisenatide were most commonly associated with nausea and vomiting, while lixisenatide and liraglutide ranked first and second for the incidence of diarrhea [45]. In our analysis, the risk of GI-related AEs with once-weekly semaglutide was similar to all other GLP-1 RA comparators, suggesting that the increased efficacy of onceweekly semaglutide vs other GLP-1 RAs is not associated with a higher risk of AEs.

The strengths of this study include the quality and homogeneity of trials included across the networks. All included data were derived from a SLR, ensuring that all evidence was captured for the analyses. Furthermore, the NMAs were performed according to previously published guidelines [28, 47-50], and the sensitivity analyses confirmed the robustness of the results and conclusions. This study was also subject to some limitations. Firstly, there was heterogeneity in the time points reported in the individual studies, which was addressed by using the wellestablished approach of applying a time window to the analyses [51-53]. Secondly, although the risk of publication bias in this analysis was considered low, four of the publications included across these analyses were open-label studies, which can introduce performance bias. Lastly, an analysis to assess the risk of hypoglycemia with 
once-weekly semaglutide (in combination with insulin) compared with other GLP-1 RAs was not feasible. In general, GLP-1 RAs can complement basal insulin therapy without the increased risk of hypoglycemia associated with basal-bolus insulin therapy [13]; often, the addition of GLP-1 RAs allows for the insulin dose to be reduced, decreasing the risk of hypoglycemia and weight gain $[15,54]$. Furthermore, in a meta-analysis assessing the efficacy and safety of GLP-1 RAs as an add-on to basal insulin vs basal insulin with or without rapid-acting insulin, insulin with GLP-1 RA was associated with a significantly lower risk of hypoglycemia compared with treatment intensification with a rapid-acting insulin [55]. For once-weekly semaglutide, the data from SUSTAIN 5 [20] suggest that the addition of onceweekly semaglutide 0.5 or $1.0 \mathrm{mg}$ to basal insulin is not associated with a significant increase in hypoglycemia compared with placebo (data unpublished). Therefore, it is likely that onceweekly semaglutide will not increase the risk of hypoglycemia when added to basal insulin; however, comparative data with other GLP-1 RAs are required.

\section{CONCLUSION}

Overall, once-weekly semaglutide $1.0 \mathrm{mg}$ as an add-on to basal insulin is the most efficacious GLP-1 RA in terms of reductions in $\mathrm{HbA}_{1 \mathrm{c}}$ and body weight from baseline after 6 months of treatment. Once-weekly semaglutide $0.5 \mathrm{mg}$ is also efficacious in reducing $\mathrm{HbA}_{1 \mathrm{c}}$ compared with the majority of GLP-1 RA comparators in the analysis. The increased efficacy of once-weekly semaglutide vs other GLP-1 RA comparators was not associated with an increase in GI-related AEs.

\section{ACKNOWLEDGEMENTS}

Funding. The study and article processing charges were funded by Novo Nordisk. All authors had full access to all of the data in this study and take complete responsibility for the integrity of the data and accuracy of the data analysis.
Editorial and Other Assistance. Editorial assistance in the preparation of this manuscript was provided by Katrin Nather of DRG Abacus. The systematic literature review was conducted by Steve Kanters of Precision Xtract. Both were funded by Novo Nordisk.

Authorship. All named authors meet the International Committee of Medical Journal Editors (ICMJE) criteria for authorship for this manuscript, take responsibility for the integrity of the work as a whole, and have given final approval to the version to be published.

Disclosures. Lars Wilkinson is an employee of Novo Nordisk. Divina Glah is an employee of and shareholder in Novo Nordisk. Hrvoje Vrazic is an employee of and shareholder in Novo Nordisk. Neil Webb is an employee of DRG Abacus. Michal Witkowski is an employee of DRG Abacus. Alan Weids is an employee of DRG Abacus.

Compliance with Ethics Guidelines. This article does not contain any new studies with human or animal subjects performed by any of the authors.

Data Availability. The datasets generated and/or analyzed during the current study are available from the corresponding author on reasonable request.

Open Access. This article is distributed under the terms of the Creative Commons Attribution-NonCommercial 4.0 International License (http://creativecommons.org/licenses/ by-nc/4.0/), which permits any noncommercial use, distribution, and reproduction in any medium, provided you give appropriate credit to the original author(s) and the source, provide a link to the Creative Commons license, and indicate if changes were made.

\section{REFERENCES}

1. The Diabetes Control and Complications Trial Research Group. The effect of intensive treatment of diabetes on the development and progression of 
long-term complications in insulin-dependent diabetes mellitus. N Engl J Med. 1993;329(14):977-86.

2. Stratton IM, Adler AI, Neil HA, Matthews DR, Manley SE, Cull CA, et al. Association of glycaemia with macrovascular and microvascular complications of type 2 diabetes (UKPDS 35): prospective observational study. BMJ. 2000;321(7258):405-12.

3. Inzucchi SE, Bergenstal RM, Buse JB, Diamant M, Ferrannini E, Nauck $M$, et al. Management of hyperglycaemia in type 2 diabetes, 2015: a patientcentred approach. Update to a position statement of the American Diabetes Association and the European Association for the Study of Diabetes. Diabetologia. 2015;58(3):429-42.

4. International Diabetes Federation. IDF clinical practice recommendations for managing type 2 diabetes in primary care. 2017. https://www.idf.org/ e-library/guidelines/128-idf-clinical-practice-recom mendations-for-managing-type-2-diabetes-in-primarycare.html. Accessed Feb 2018.

5. Handelsman Y, Bloomgarden ZT, Grunberger G, Umpierrez G, Zimmerman RS, Bailey TS, et al. American association of clinical endocrinologists and american college of endocrinology-clinical practice guidelines for developing a diabetes mellitus comprehensive care plan-2015. Endocr Pract. 2015;21(Suppl 1):1-87.

6. American Diabetes Association. Standards of medical care in diabetes-2018. Diabetes Care. 2018;41(suppl 1):S1-S159.

7. Garber AJ, Abrahamson MJ, Barzilay JI, Blonde L, Bloomgarden ZT, Bush MA, et al. Consensus statement by the American Association of Clinical Endocrinologists and American College of Endocrinology on the comprehensive type 2 diabetes management algorithm-2018 executive summary. Endocr Pract. 2018;24(1):91-120.

8. Canadian Diabetes Association Clinical Practice Guidelines Expert C, Goldenberg R, Punthakee Z. Definition, classification and diagnosis of diabetes, prediabetes and metabolic syndrome. Can J Diabetes. 2013;37(Suppl 1):S8-11.

9. Mauricio D, Meneghini L, Seufert J, Liao L, Wang H, Tong L, et al. Glycaemic control and hypoglycaemia burden in patients with type 2 diabetes initiating basal insulin in Europe and the USA. Diabetes Obes Metab. 2017;19(8):1155-64.

10. Dale J, Martin S, Gadsby R. Insulin initiation in primary care for patients with type 2 diabetes: 3-year follow-up study. Prim Care Diabetes. 2010;4(2):85-9.
11. Garber AJ. Long-acting glucagon-like peptide 1 receptor agonists: a review of their efficacy and tolerability. Diabetes Care. 2011;34(Suppl 2):S279-84.

12. Prasad-Reddy L, Isaacs D. A clinical review of GLP-1 receptor agonists: efficacy and safety in diabetes and beyond. Drugs Context. 2015;4:212283.

13. Giorgino F, Bonadonna RC, Gentile S, Vettor R, Pozzilli P. Treatment intensification in patients with inadequate glycemic control on basal insulin: rationale and clinical evidence for the use of shortacting and other glucagon-like peptide-1 receptor agonists. Diabetes Metab Res Rev. 2016;32(6):497-511.

14. Eng C, Kramer CK, Zinman B, Retnakaran R. Glucagon-like peptide-1 receptor agonist and basal insulin combination treatment for the management of type 2 diabetes: a systematic review and meta-analysis. Lancet. 2014;384(9961):2228-34.

15. Balena R, Hensley IE, Miller S, Barnett AH. Combination therapy with GLP-1 receptor agonists and basal insulin: a systematic review of the literature. Diabetes Obes Metab. 2013;15(6):485-502.

16. Sorli C, Harashima SI, Tsoukas GM, Unger J, Karsbol JD, Hansen T, et al. Efficacy and safety of onceweekly semaglutide monotherapy versus placebo in patients with type 2 diabetes (SUSTAIN 1): a doubleblind, randomised, placebo-controlled, parallelgroup, multinational, multicentre phase $3 \mathrm{a}$ trial. Lancet Diabetes Endocrinol. 2017;5(4):251-60.

17. Ahren B, Masmiquel L, Kumar H, Sargin M, Karsbol JD, Jacobsen SH, et al. Efficacy and safety of onceweekly semaglutide versus once-daily sitagliptin as an add-on to metformin, thiazolidinediones, or both, in patients with type 2 diabetes (SUSTAIN 2): a 56-week, double-blind, phase 3a, randomised trial. Lancet Diabetes Endocrinol. 2017;5(5):341-54.

18. Hramiak I, Ahmann A, Capethorn M, Charpentier G, Dotta F, Lingvay EH, et al. Efficacy and safety of once-weekly semaglutide vs. exenatide ER after 56 weeks in subjects with type 2 diabetes (SUSTAIN 3). Can J Diabetes. 2016;40(5):S41.

19. Aroda VR, Bain SC, Cariou B, Piletic M, Rose L, Axelsen M, et al. Efficacy and safety of once-weekly semaglutide versus once-daily insulin glargine as add-on to metformin (with or without sulfonylureas) in insulin-naive patients with type 2 diabetes (SUSTAIN 4): a randomised, open-label, parallel-group, multicentre, multinational, phase 3a trial. Lancet Diabetes Endocrinol. 2017;5(5):355-66. 
20. Rodbard H, Lingvay I, Reed J, de la Rosa R, Rose L, Sugimoto D, et al. Efficacy and safety of semaglutide once-weekly vs placebo as add-on to basal insulin alone or in combination with metformin in subjects with type 2 diabetes (SUSTAIN 5). Diabetologia. 2016;59(suppl. 1):S364.

21. Marso SP, Bain SC, Consoli A, Eliaschewitz FG, Jodar E, Leiter LA, et al. Semaglutide and cardiovascular outcomes in patients with type 2 diabetes. N Engl J Med. 2016;375(19):1834-44.

22. Pratley RE, Aroda VR, Lingvay I, Lüdemann J, Andreassen C, Navarria A, Viljoen A. SUSTAIN 7 investigators. Semaglutide versus dulaglutide once weekly in patients with type 2 diabetes (SUSTAIN 7): a randomised, open-label, phase $3 \mathrm{~b}$ trial. Lancet Diabetes Endocrinol. 2018;6(4):275-86.

23. Trujillo JM, Nuffer W, Ellis SL. GLP-1 receptor agonists: a review of head-to-head clinical studies. Ther Adv Endocrinol Metab. 2015;6(1):19-28.

24. Witkowski M, Wilkinson L, Webb N, Weids A, Glah D, Vrazic H. A systematic literature review and network meta-analysis comparing once-weekly semaglutide with other GLP-1 receptor agonists in patients with type 2 diabetes previously receiving 1-2 oral anti-diabetic drugs. Diabetes Ther. 2018. https://doi.org/10.1007/s13300-018-0424-2.

25. GSK. Albiglutide withdrawal letter. 2017. https:// www.gsksource.com/pharma/content/dam/ GlaxoSmithKline/US/en/Brands/TANZEUM/824058 R0_hcpLetter.pdf. Accessed Feb 2018.

26. National Institute for Health and Care Excellence. Single technology appraisal: user guide for company evidence submission template. 2015. https://www.nice.org.uk/process/pmg24/resources/ single-technology-appraisal-user-guide-for-companyevidence-submission-template-pdf-72286715419333. Accessed Mar 2018.

27. Lunn D, Jackson C, Best N, Thomas A, Spiegelhalter D. The BUGS book: a practical introduction to Bayesian analysis. Boca Raton: CRC Press; 2013.

28. Dias S, Welton NJ, Sutton AJ, Caldwell DM, Lu G, Ades AE. NICE DSU technical support document 4: inconsistency in networks of evidence based on randomised controlled trials. 2011. http://www. nicedsu.org.uk. Last updated April 2014.

29. Miladinovic B, Hozo I, Chaimani A, Djulbegovic B. Indirect treatment comparison. Stata J. 2014;14(1):76-86.

30. Pozzilli P, Norwood P, Jodar E, Davies MJ, Ivanyi T, Jiang $\mathrm{H}$, et al. Placebo-controlled, randomized trial of the addition of once-weekly glucagon-like peptide- 1 receptor agonist dulaglutide to titrated daily insulin glargine in patients with type 2 diabetes (AWARD-9). Diabetes Obes Metab. 2017;19(7):1024-31.

31. Buse JB, Bergenstal RM, Glass LC, Heilmann CR, Lewis MS, Kwan AY, et al. Use of twice-daily exenatide in basal insulin-treated patients with type 2 diabetes: a randomized, controlled trial. Ann Intern Med. 2011;154(2):103-12.

32. Diamant M, Nauck MA, Shaginian R, Malone JK, Cleall S, Reaney M, et al. Glucagon-like peptide 1 receptor agonist or bolus insulin with optimized basal insulin in type 2 diabetes. Diabetes Care. 2014;37(10):2763-73.

33. Riddle MC, Forst $\mathrm{T}$, Aronson R, Sauque-Reyna L, Souhami E, Silvestre L, et al. Adding once-daily lixisenatide for type 2 diabetes inadequately controlled with newly initiated and continuously titrated basal insulin glargine: a 24-week, randomized, placebo-controlled study (GetGoal-Duo 1). Diabetes Care. 2013;36(9):2497-503.

34. Rosenstock J, Guerci B, Hanefeld M, Gentile S, Aronson R, Tinahones FJ, et al. prandial options to advance basal insulin glargine therapy: testing lixisenatide plus basal insulin versus insulin glulisine either as basal-plus or basal-bolus in type 2 diabetes: the GetGoal Duo-2 trial. Diabetes Care. 2016;39(8):1318-28.

35. Riddle MC, Aronson R, Home P, Marre M, Niemoeller E, Miossec P, et al. Adding once-daily lixisenatide for type 2 diabetes inadequately controlled by established basal insulin: a 24-week, randomized, placebo-controlled comparison (GetGoal-L). Diabetes Care. 2013;36(9): 2489-96.

36. Seino Y, Min KW, Niemoeller E, Takami A, Investigators EG-LAS. Randomized, double-blind, placebo-controlled trial of the once-daily GLP-1 receptor agonist lixisenatide in Asian patients with type 2 diabetes insufficiently controlled on basal insulin with or without a sulfonylurea (GetGoal-L-Asia). Diabetes Obes Metab. 2012;14(10):910-7.

37. Yang W, Min K, Zhou Z, Li L, Xu X, Zhu D, et al. Efficacy and safety of lixisenatide in a predominantly Asian population with type 2 diabetes insufficiently controlled with basal insulin: the GetGoal-L-C randomized trial. Diabetes Obes Metab. 2018;20(2):335-43.

38. Meneilly GS, Roy-Duval C, Alawi H, Dailey G, Bellido $\mathrm{D}$, Trescoli $\mathrm{C}$, et al. Lixisenatide therapy in older patients with type 2 diabetes inadequately controlled on their current antidiabetic treatment: the GetGoal-O randomized trial. Diabetes Care. 2017;40(4):485-93. 
39. Rosenstock J, Fonseca VA, Gross JL, Ratner RE, Ahren B, Chow FC, et al. Advancing basal insulin replacement in type 2 diabetes inadequately controlled with insulin glargine plus oral agents: a comparison of adding albiglutide, a weekly GLP-1 receptor agonist, versus thrice-daily prandial insulin lispro. Diabetes Care. 2014;37(8):2317-25.

40. Ahmann A, Rodbard HW, Rosenstock J, Lahtela JT, de Loredo L, Tornoe K, et al. Efficacy and safety of liraglutide versus placebo added to basal insulin analogues (with or without metformin) in patients with type 2 diabetes: a randomized, placebo-controlled trial. Diabetes Obes Metab. 2015;17(11):1056-64.

41. Kim YG, Hahn S, Oh TJ, Park KS, Cho YM. Differences in the HbA1c-lowering efficacy of glucagonlike peptide- 1 analogues between Asians and nonAsians: a systematic review and meta-analysis. Diabetes Obes Metab. 2014;16(10):900-9.

42. FDA. Guidance for industry, diabetes mellitus: developing drugs and therapeutic biologics for treatment and prevention. Silver Spring, MD: Food and Drug Administration; 2008.

43. Committee for Proprietary Medicinal Products, European Agency for Evaluation of Medicinal Products (EMA). EMEA/CPMP/EWP/1080/00Rev.1: guideline on clinical investigation of medicinal products in the treatment of diabetes mellitus. 2012. http://www.ema.europa.eu/docs/en_GB/ document_library/Scientific_guideline/2012/06/ WC500129256.pdf. Accessed 4 Sep 2017.

44. Salanti G, Ades AE, Ioannidis JP. Graphical methods and numerical summaries for presenting results from multiple-treatment meta-analysis: an overview and tutorial. J Clin Epidemiol. 2011;64(2):163-71.

45. Sun F, Chai S, Yu K, Quan X, Yang Z, Wu S, et al. Gastrointestinal adverse events of glucagon-like peptide- 1 receptor agonists in patients with type 2 diabetes: a systematic review and network metaanalysis. Diabetes Technol Ther. 2015;17(1):35-42.

46. Mathieu C, Rodbard HW, Cariou B, Handelsman Y, Philis-Tsimikas A, Ocampo Francisco AM, et al. A comparison of adding liraglutide versus a single daily dose of insulin aspart to insulin degludec in subjects with type 2 diabetes (BEGIN: VICTOZA ADD-ON). Diabetes Obes Metab. 2014;16(7): 636-44.
47. Hoaglin DC, Hawkins N, Jansen JP, Scott DA, Itzler $\mathrm{R}$, Cappelleri JC, et al. Conducting indirect-treatment-comparison and network-meta-analysis studies: report of the ISPOR Task Force on Indirect Treatment Comparisons Good Research Practices: part 2. Value Health. 2011;14(4):429-37.

48. Dias S, Welton NJ, Sutton AJ, Ades AE. NICE DSU technical support document 2: a generalised linear modelling framework for pairwise and network meta-analysis of randomised controlled trials. 2011. http://www.nicedsu.org.uk. Accessed 4 Sep 2017.

49. Dias S, Welton NJ, Sutton AJ, Valdwell DM, Guobing L, Ades AE. NICE DSU technical support document 3: heterogeneity: subgroups, meta-regression, bias and bias-adjustment. 2011. http://www. nicedsu.org.uk. Accessed 4 Sep 2017.

50. Higgins JPT, Green S. Cochrane handbook for systematic reviews of interventions version 5.0.2 (updated September 2009). 2009. http://www. cochrane-handbook.org.

51. Barnett $\mathrm{AH}$, Orme ME, Fenici P, Townsend R, Wygant G, Roudaut M. Systematic review and network meta-analysis to compare dapagliflozin with other diabetes medications in combination with metformin for adults with type 2 diabetes. Intern Med. 2014;S6:006.

52. Kayaniyil S, Lozano-Ortega G, Bennett HA, Johnsson K, Shaunik A, Grandy S, et al. A network metaanalysis comparing exenatide once weekly with other GLP-1 receptor agonists for the treatment of type 2 diabetes mellitus. Diabetes Ther. 2016;7(1):27-43.

53. Orme ME, Nguyen H, Lu JY, Thomas SA. Comparative effectiveness of glycemic control in patients with type 2 diabetes treated with GLP-1 receptor agonists: a network meta-analysis of placebo-controlled and active-comparator trials. Diabetes Metab Syndr Obes. 2017;10:111-22.

54. Vora J. Combining incretin-based therapies with insulin: realizing the potential in type 2 diabetes. Diabetes Care. 2013;36(Suppl 2):S226-32.

55. Wysham CH, Lin J, Kuritzky L. Safety and efficacy of a glucagon-like peptide-1 receptor agonist added to basal insulin therapy versus basal insulin with or without a rapid-acting insulin in patients with type 2 diabetes: results of a meta-analysis. Postgrad Med. 2017;129(4):436-45. 